\title{
Psychopharmacology training
}

A point of view*

\author{
I.N. Ferrier and S.J. Cooper
}

There has been a recent welcome increase in public and political awareness of mental health problems, together with a growing understanding of the need for services for those with severe mental illness, a widespread acceptance of the need for more resources in the community and primary care and agreement on the importance of medication in the treatment of several psychiatric disorders. This increased public awareness brings with it close examination of our practice.

There have been a number of scandals about mental health care in the UK in the past two decades, largely centred on restrictive regimes and controversial clinical policies. Increasingly, however, media attention has focused on pharmacological practice. With some recent TV programmes having been biased, and cases taken out of context, psychiatrists and psychopharmacologists cannot be complacent. While there has been considerable success in developing scientifically demonstrated effective treatments, psychiatrists have a responsibility in their treatment decisions to balance the benefits of drugs against the risks. Scientific knowledge and clinical practice are improving, but the rate of improvement of the latter is at least maintained, if not enhanced.

General knowledge about psychopharmacology in the caring professions in the UK is patchy. The subject is often taught inadequately in medical school and can fall between the stools of clinical pharmacology and psychiatry. It would seem of considerable benefit to have joint teaching by the two disciplines (for the teachers as much as the taught). Other disciplines such as nurses and social workers are given little information about drugs and so are unable to question doctors about their psychopharmacological practice and are unclear themselves about appropriate treatment. Yet it is often nurses to whom patients turn for reassurance about their treatment. The level of training in psychopharmacological prescribing for GPs is inadequate. Inappropriate prescribing in primary care is

- This article is based on a recent contribution to the British Association of Psychopharmacology's Newsletter. still common and, even when the right drug is chosen, the dose is often inadequate or the drug prescribed for too little or too long. The level of prescribing of drugs increases with the publicity given to particular compounds and this trend seems even more evident in the case of psychotropics.

Psychiatrists in training are often given inadequate psychopharmacological advice. Myths build up in registrars' minds. For example, some believe the dose of antidepressants for the elderly should always be very low "as the elderly don't have the neurones to cope with high doses" whereas what is required is careful titration of dose. Faulty prescribing habits and lack of imagination in changing regimes or trying combinations are widespread. Some of the problems of high dose neuroleptic administration originate from lack of basic pharmacological understanding of the trainer and lack of enquiry from the trainee. There is a general reluctance among the psychiatric profession to admit to these problems. Recently, we were distressed to hear of a registrar saying that he would not look up the dose of a drug in front of the patient as this was a sign of "weakness". The average patient looking at the bulkiness of the Data Sheet Compendium would be much more reassured if a doctor looked up doses, side effects and interactions there and then. We feel that there should be formalised psychopharmacology teaching on MRCPsych courses and, if course organisers feel they do not have specific expertise, arrangements should be made for it to be drafted in. There is also a case for a specific psychopharmacological paper in the membership examination and Part 2 MRCPsych candidates should be questioned in detail about how they would treat their patient and what they would do if side effects occurred or there was no response. The Royal College of Psychiatrists should increase its efforts to promote continuing medical education (CME) with psychopharmacology as a high priority topic.

No-one can be an expert in all fields. Most major psychiatric units or district services usually have clinicians with special training and responsibility for particular aspects of 
psychiatry, such as psychogeriatrics, psychotherapy, and substance abuse. Should we not actively encourage the appointment of one local clinician in such services who has additional training and academic experience in psychopharmacology. Of course such a person would not take over the care of all drug-treated patients (psychotherapists do not take on all patients given psychotherapy) but he or she would be available to give local advice and perhaps take on more complex cases. Although the College has special Sections/Groups for General Psychiatry and Biological Psychiatry neither specifically deals with psychopharmacology. The help of such organisations as the British Association for Psychopharmacology (BAP) could be enlisted to identify existing consultants and academic units where interested clinicians could obtain training.

There is a need to improve continuing medical education particularly as psychopharmacology is a changing and evolving subject. This could be done by greater encouragement of local regional meetings. Half-day meetings on an annual or bi-annual basis with a mixed content relating to new developments and treatments as well as basic pharmacology/pharmacological principles could fulfil this. The British Association of Psychopharmacology could produce a panel of speakers and topics from which local organisers could choose as well as by encouraging industry sponsorship. Such meetings should contain much more than lectures on new treatments, to avoid any fear of industry domination and also to wean clinicians away from the notion that pharmacological practice can be solved by a 'recipe book' approach rather than proper understanding of basic principles.

Great advances have been made in psychopharmacology and there are more to come. This momentum needs to be maintained to ensure that the most appropriate use is made of the expanding psychopharmacological armamentarium. Indeed this expansion, with the development of apparently safer and more selective drugs, emphasises the need for improved training/continuing education. The developments of the last ten years have widened our prescribing choice more than for any period since the mid-1960s. It is in everyone's interest to ensure we have our house in order and that inappropriate prescribing is reduced to the minimum. If psychiatrists do not prescribe drugs scientifically and carefully then our role may be under even more threat.

I.N. Ferrier, Professor, Department of Psychiatry, School of Neuroscience, University of Neucastle upon Tyne NE1 4LP; and S.J. Cooper, Sentor Lecturer, Department of Mental Health. The Queen's Universty of Belfast, BT9 7BL 